\title{
A IMPLEMENTAÇÃO DE PRINCÍPIOS AGROFLORESTAIS E SUA IMPORTÂNCIA NO DESENVOLVIMENTO DOS AGROECOSSISTEMAS: EXPERIÊNCIA NO ASSENTAMENTO SANTA HELENA, SÃO CARLOS (SP)
}

Isabela Tambarussi Bozzo Rodolfo Antônio de Figueiredo ${ }^{2}$

Resumo: A insustentabilidade da agricultura moderna convencional aponta para a necessidade de criar alternativas sociais e ecológicas que a superem. Nesse sentido, o objetivo desse trabalho foi investigar o processo de aprendizagem, junto a assentados(as) ${ }^{3}$ rurais, gerado através de uma ação extensionista de caráter participativo, baseada na transmissão dos princípios de Sistemas Agroflorestais, com o intuito de dialogar sobre sua importância no equilíbrio, resiliência e diversificação na produtividade dos agroecossistemas. Através do mapeamento do local, foram levantadas as dificuldades e a partir da análise das informações obtidas foi possível concluir que todas elas se relacionam intimamente, pois são aspectos que necessitam estar em construção conjunta para o desenvolvimento de uma produção agroecológica. Através das vivências, observamos as potencialidades de aprendizado e que as limitações não são locais, mas elas estão presentes em diversas comunidades produtoras de alimentos agroecológicos, em diferentes níveis. Percebemos a questão do reconhecimento e fortalecimento do coletivo o principal eixo a ser trabalhado no local.

Palavras-chave: Assentamento Rural; SAF; Metodologia Participativa; Agroecologia.

\footnotetext{
'Bacharel em Ciências Biológicas, Universidade Federal de São Carlos. Educadora da Escola da Toca (Instituto Toca/Fazenda da Toca)

2Professor Associado do Departamento de Ciências Ambientais (DCAm) e do Programa de Pós-Graduação em Ciências Ambientais (PPGCAm) da Universidade Federal de São Carlos. ${ }^{3}$ Neste artigo será utilizada a linguagem não-sexista, seguindo Casellato et al. (1996).
}

ABSTRACT: The unsustainability of conventional modern agriculture points to the need to create social and ecological alternatives that surpass it. In this sense, the objective of this work was to investigate the learning process, together with rural settlers, generated through an extensionist action of participatory character, based on the transmission of the principles of Agroforestry Systems, in order to discuss their importance in the balance, resilience and diversification in the productivity of agroecosystems. Through the mapping of the site, the difficulties were raised and from the analysis of the information obtained, it was possible to conclude that all of them are closely related, since these are aspects that need to be in joint construction for the development of an agroecological production. Through the experiences, we observe the potential of learning and that the limitations are not local, but they are present in several agro-ecological food producing communities at different levels. We perceive the issue of recognition and strengthening of the collective the main axis to be worked on the site.

KEYwORDS: Rural Settlement; AFS; Participatory Methodology; Agroecology.

\section{INTRODUÇão}

Apesar da prática da agricultura ter mais de 10.000 anos, foi a partir da Revolução Industrial (séc. XVIII-XIX) que houve uma grande modificação em sua estrutura física, econômica e tecnológica, caracterizada principalmente pela utilização de grandes maquinários, produção em larga escala e a integração da pecuária na produção. A estruturação de um novo modelo de sociedade, em escala política e econômica, trouxe diversas demandas de produção, alinhando o desenvolvimento às práticas agrícolas. A partir desse momento, instaura-se a denominada Agricultura Moderna (EHLERS, 1996).

Com o contínuo crescimento do capitalismo e da industrialização, os investimentos financeiros e tecnológicos na agricultura levam a uma grande expansão de territórios, aumentando muito a produção e exploração do solo. Assim, em longo prazo, surge uma primeira limitação aos rendimentos agrícolas: a diminuição e o desequilíbrio dos fertilizantes naturais do solo, trazendo a necessidade de implementação por insumos e corretivos (MAZOYER; ROUDART, 2009).

A conjuntura política e econômica que segue culmina na segunda Revolução Industrial (1850-1870) e Segunda Guerra Mundial (1939-1945), 
um período de intenso desenvolvimento de diversos setores industriais (químico, elétrico, alimentício), levando à implantação de práticas na agricultura que modificarão crucialmente seu caráter. Prioriza-se um modelo tecnológico agrícola baseado no preparo intensivo do solo, uso de adubos minerais de alta solubilidade e agrotóxicos, além da contínua seleção das variedades de plantas e raças de animais. Apesar da incontestável elevação da produtividade das culturas, a adoção dessas práticas inadequadas gerou inúmeros problemas ambientais, como a degradação dos solos pela exposição, compactação e perda de nutrientes naturais, impactos e contaminação dos recursos hídricos, e diminuição da biodiversidade (KAMIYAMA, 2009).

O contexto ambiental atual caracteriza-se pela nítida influência das mudanças climáticas, com a incidência cada vez mais frequente de desastres naturais e desequilíbrios nos ecossistemas (SOSA et al., 2013). Por outro lado, a crescente preocupação da sociedade com o meio ambiente tem produzido reflexos nos sistemas de produção agrícola, uma vez que a demanda mundial por alimentos mais saudáveis, produzidos através de modelos sustentáveis, se consolida (PATERNIANI, 2001). A insustentabilidade da agricultura moderna convencional aponta para a necessidade de criar alternativas sociais e ecológicas que a superem.

Segundo alguns autores (ALTIERI, 2012; CASADO et al., 2000; COSTA, 2017; CAPORAL; COSTABEBER, 2004), a Agroecologia é um campo de conhecimento interdisciplinar, que contém princípios básicos para o desenho, manejo e construção de sistemas agrícolas sustentáveis, denominados Agroecossistemas. Ela emerge na inclusão de diversas áreas, como Ecologia, Agronomia, Ciências Humanas, e contribui na desconstrução dos meios de produção convencional que causam degradação ecológica e social, e constrói um paradigma de inclusão, sustentabilidade e emancipação. Nessa perspectiva, a Agroecologia surge não somente como meio de superação dos métodos convencionais de produção, mas também traz bases científicas princípios, conceitos e metodologias - que possibilitam a transição de uma agricultura convencional para uma ecológica através de um olhar inovador.

No Brasil, assim como diversos países, a expansão do uso dos agrocombustíveis - combustíveis extraídos de produtos agrícolas - e as práticas associadas à sua produção têm sido grandes intensificadoras dos impactos ecológicos, tais como o desmatamento, perda de habitats, uso de transgênicos e de insumos agroquímicos, esgotamento de recursos hídricos, entre outros fatores (ALTIERI, 2012; TEIXEIRA; COUTO, 2013).
Nosso país é considerado o maior produtor mundial de cana-de-açúcar, produzindo $60 \%$ de todo o etanol derivado da planta, totalizando três milhões de hectares da cultura. A soja e a cana-de-açúcar ocupam $21 \%$ da área total cultivada no país, mais terras do que qualquer outro cultivo, enquanto a produção de alimentos para a população através da Agricultura Familiar detém 30\% do total das terras agrícolas (ALTIERI, 2012).

A estruturação das técnicas e métodos de plantio através da agricultura convencional agride e causa danos não somente ao meio ambiente, mas também compromete diretamente a saúde e segurança alimentar da população. Segundo dados fornecidos pela Associação Brasileira de Saúde Coletiva - ABRASCO, o Brasil é o país campeão no consumo de agrotóxicos, sendo 7,0 litros per capita/ano, o que resulta em mais de 70 mil intoxicações agudas ou crônicas no mesmo período.

Em um panorama mundial, passamos por uma "crise alimentar", em que enormes parcelas de terras são destinadas a cultivos para fins econômicos. Perdemos a autonomia sobre o cultivo dos alimentos, dependendo de insumos agroquímicos, organismos geneticamente modificados, além da grande redução da diversidade no que consumimos.

Segundo Miguel Altieri:

A agricultura mundial se reduziu ao plantio de 70 espécies (12 espécies de grãos, 23 espécies de hortaliças e 35 espécies de frutas e nozes), e estas são utilizadas na base da alimentação humana em todas as culturas, ocupando, portanto, 1,44 bilhão de hectares de terra. Assim, se compararmos a paisagem agrícola com ecossistemas naturais, notaremos que houve uma "simplificação" dentro da estrutura ambiental, pois em apenas 1 hectare de floresta tropical há, geralmente, mais de 100 espécies de árvores (ALTIERI, 2012, p. 24).

O grande desafio, então, se mostra na produção de alimentos através de uma agricultura regenerativa, baseada em princípios e métodos que não agridam o meio ambiente e, ao mesmo tempo, garantam uma soberania alimentar, diversidade na produção, autonomia e emancipação dos(as) agricultores(as), combinados com a manutenção da biodiversidade e equilíbrio dos ecossistemas (CASADO et al., 2000).

Dentro da perspectiva Agroecológica, Ernst Götsch ${ }^{4}$ traz conceitos

${ }^{4}$ As informações citadas neste parágrafo sobre Ernst Götsch foram retiradas da página Agenda Götsch, o site oficial de seu trabalho. Disponível em: $<$ http://agendagotsch.com/pt/ernst $>$, acesso em 03/09/2018. 
aprimorados sobre um modelo de agricultura sustentável: a produção através de Sistemas Agroflorestais, hoje definidos por ele como "Agricultura Sintrópica". A Agrofloresta se define, resumidamente, em um conjunto de princípios e técnicas que buscam integrar a produção de alimentos à dinâmica de regeneração natural de florestas.

De acordo com Franco (2000), os Sistemas Agroflorestais (SAFs) configuram-se como uma ferramenta de grande potencial ao confrontar o uso da terra nos sistemas convencionais, pois são capazes de fornecer bens e serviços, integrando diversas atividades produtivas. Os SAFs são uma opção viável para os agricultores familiares, pois representam um novo enfoque de desenvolvimento rural pela utilização da diversidade (árvores, arbustos, culturas agrícolas e/ou animais), trazendo um modelo de cultivo inovador, e não uma simples técnica agrícola ou florestal, que objetiva o aumento de produção.

Segundo Götsch (1995 apud STEENBOCK; VEZZANI, 2013, p. 8) diz ser:

Os sistemas agroflorestais, conduzidos numa lógica agroecológica transcendem os modelos agrícolas prontos, e sugerem sustentabilidade por partirem de conceitos básicos fundamentais, aproveitando conhecimentos locais e desenhando sistemas adaptados para o local. A ideia é, em essência, imitar a natureza em seus processos e interações, e somente através de agroecossistemas que pareçam em sua forma, estrutura e dinâmica ao ecossistema natural original do local de intervenção, é possível alcançar a sustentabilidade.

A agrofloresta expressa a capacidade de produtividade e renda, integrando espécies de ciclos diferentes - curto, médio e longo - em um sistema produtivo complexo, trazendo alta produtividade pela exploração da natureza como recurso e aliada, em que é racionalmente cultivada e preservada (NUNES; SILVA, 2016). Essa recriação de um modelo agrícola que integra as diretrizes econômicas, sociais e ambientais é revolucionária.

O objetivo principal deste trabalho consiste em investigar o processo de aprendizagem, junto aos(às) assentados(as) rurais, gerado através de uma ação extensionista baseada na transmissão dos princípios de Sistemas Agroflorestais, com o intuito de dialogar sobre sua importância no equilíbrio, resiliência e diversificação na produção dos agroecossistemas. As ações extensionistas principais foram: aproximação e conhecimento do grupo de trabalho; mutirões (implementação de princípios agroflorestais em ação coletiva); reuniões com o coletivo para conhecimento do projeto e planejamento das práticas; fortalecimento da comunidade através da aproximação das famílias assentadas; e troca de conhecimentos entre o grupo.

\section{Metodologia}

\section{Área de Estudo}

O presente trabalho foi realizado no Assentamento Santa Helena, localizado na área rural do Município de São Carlos (SP), criado em 2005 na modalidade de Projeto de Desenvolvimento Sustentável (PDS), política instaurada pelo Instituto Nacional de Colonização e Reforma Agrária (INCRA) através da portaria $n^{\circ} 477 / 99$, que visa articular a gestão sustentável dos recursos naturais com o fortalecimento socioeconômico das famílias.

O Assentamento possui, em área total, 102,5 ha, divididos em lotes individuais de aproximadamente 5,4 ha., destinados a moradia e produção de 14 famílias, além de uma área comunitária, Reserva Legal (6,56 ha), e Áreas de Preservação Permanentes - APPs - que totalizam 4,28 ha. Caracteriza-se por uma vegetação de transição entre Floresta Estacional Semidecidual (Mata Atlântica) e Cerradão (Cerrado), com predominância de solo de textura arenosa (Latossolo Vermelho), e clima tropical de altitude com inverno seco (LOPES et al., 2014).

Anteriormente à implantação do PDS na área, o local era denominado Fazenda Santa Helena, arrendada para o plantio e fornecimento de canade-açúcar para a Usina Ipiranga (Descalvado-SP), além de exploração de avicultura de corte (SARAVALLE et al., 2015). A transformação deste território do capital em um território camponês vem ocorrendo há algum tempo e a ação das pessoas assentadas com diferentes grupos auxiliaram na implantação de arranjos produtivos sustentáveis (LOPES et al., 2017). Atualmente, todas as famílias produzem alimentos, porém dentre todas são sete famílias que produzem alimentos orgânicos para subsistência e comercialização. Além disso, algumas pessoas do Assentamento possuem trabalhos na cidade e, assim, complementam sua renda.

\section{Coleta de Dados}

A metodologia deste trabalho foi baseada em algumas técnicas da Metodologia Comunicativa Crítica (GÓMEZ et al., 2006), no intuito de envolver os(as) agricultores(as) nos processos participativos propostos, buscando favorecer a capacidade de observação dos espaços, interpretação 
dos problemas/dificuldades, e elaboração de alternativas/respostas próprias, de acordo com suas demandas, de uma forma dialógica e reflexiva.

Os dados foram coletados através de anotações em diários de campo, caminhadas transversais para avaliar os recursos e impactos, e entrevistas semiestruturadas com base em um questionário socioambiental.

Foram realizadas visitas periódicas durante o primeiro e segundo semestre de 2017, com a intenção de construir uma relação de aproximação entre a comunidade e a equipe de pesquisa. Após esse período, realizamos visitas individuais nos lotes de cada família, com o objetivo de construir um diagnóstico através de técnicas participativas de avaliação, problematizando a realidade local, suas dificuldades e principais demandas, a fim de construir um arcabouço de informações, desde o histórico da criação, ocupação e transformação do Assentamento, bem como as ações praticadas atualmente.

Para a obtenção dos dados foi utilizado o método de Diagnóstico Rural Participativo (DRP) (ALENCAR; GOMES, 1998), buscando uma análise de atores e atrizes, sistemas de interesse e relações externas, todos através das entrevistas semiestruturadas, baseadas no questionário socioambiental que elaboramos. As caminhadas transversais foram feitas na intenção de avaliação dos recursos e o levantamento dos impactos, elencando as demandas prioritárias para o trabalho através do mapeamento dos lotes.

Após esse momento, foram feitas algumas reuniões de trabalho e discussão, com a intenção de apresentar a proposta e discutir sua prática, bem como planejar conjuntamente os espaços a serem aplicadas. Assim, foram decididos os locais em que implantaríamos um sistema de cultivo baseado em princípios agroflorestais de produção, através de mutirões, utilizados também como "áreas de aprendizagem coletiva": as chamadas Unidades de experimentação participativa (UEPs).

\section{Práticas Realizadas}

As Unidades de experimentação participativa (UEPs), pensadas para funcionarem dentro de alguns lotes dos agricultores, são definidas por WHITAKER (2011) como "áreas físicas, conjunto de parcelas experimentais em um cultivo ou propriedade em rede, que possuem a vantagem de proporcionar uma apropriação natural de conhecimentos gerados no decorrer de projetos, seja pela geração de novos resultados validados pelas condições reais ou por sensibilização e intercâmbio, através de eventos de capacitação (oficinas, cursos, dias de campo, seminário)".

Os trabalhos por UEPs permitem, além de sua potencialidade prática de aprendizagem, um aprofundamento das relações entre os(as) atores e atrizes envolvidos(as) e facilitam a articulação social, fortalecimento de convergências de interesses, e possibilitam o emponderamento dos(as) agricultores(as). Nelas, são criadas conexões entre os saberes populares e científicos, que podem ser tecnológicos, metodológicos ou conceituais, transformando um local de prática em um local de debates e aprendizados, exercitando um dos principais preceitos da agroecologia: a transdisciplinaridade.

Nesse trabalho a utilização de uma unidade experimental participativa voltada para implementação de princípios agroflorestais teve o objetivo de possibilitar uma pré-visualização de processos de transição, que ocorrem em agroecossistemas desse modelo, tornando um espaço didático para construção gradual de conhecimentos, e suas vantagens orientadas à sustentabilidade.

Os princípios agroflorestais a serem implementados foram pensados e propostos de acordo com as maiores demandas locais e dificuldades elencadas nas entrevistas, como: plantio de espécies diversificadas para a produção de alimentos, fornecimento cíclico de biomassa para adubação e cobertura do solo do sistema, suprimento de água para o plantio, recurso escasso e limitado para a maioria dos(as) agricultores(as) do Assentamento.

\section{Resultados e Discussão}

\section{VISITAS E ENTREVISTAS}

A aproximação e o conhecimento do grupo de trabalho através das visitas semanais foi um processo contínuo e essencial para a compreensão da realidade local, das demandas e desafios, bem como de suas potencialidades. As visitas proporcionaram um auxílio na construção de uma relação recíproca e afetuosa entre o grupo de pesquisa e a comunidade, estreitando a relação pesquisador(a)-pesquisado(a), de tal forma a não existir objeto de pesquisa, mas sim sujeitos participantes do processo. Foi possível, através destes momentos, aprender sobre o funcionamento da comercialização de cestas de alimentos orgânicos, da estrutura desse comércio, e as parcerias necessárias para o seu acontecimento.

Para os(as) assentados(as) o momento da montagem das cestas é, muitas vezes, o único momento semanal de encontro coletivo e, por isso, dialogam não somente sobre os produtos que cada um(a) contribuiu/contribuirá nas cestas, mas também sobre as parcerias, ida às feiras urbanas, questões e problemas pessoais, manutenções do espaço, e possíveis projetos. Nesse 
aspecto, a nossa presença nesse espaço de convívio nos trouxe a possibilidade de compreensão dessa comunidade rural e dos seus integrantes, ao mesmo tempo que compartilhamos com eles(as) as ações presentes dentro da Universidade e outros locais produtores de alimentos orgânicos, partilhando também nossas vivências e conhecimentos.

A partir da construção dessa relação, realizamos as entrevistas individuais nos lotes das famílias, nos baseando no questionário socioambiental. $\mathrm{O}$ questionário teve o intuito de proporcionar um momento de diálogo livre e à vontade com os(as) assentados(as). Nos encontros buscamos dialogar sobre as vivências de cada agricultor(a) de forma particular, sua trajetória de vida e suas experiências no trabalho e cultivo de alimentos, os conhecimentos sobre métodos de produção orgânicos agroflorestais, os métodos de obtenção de renda e escoamento de seus produtos (feiras, parcerias, cestas etc.), entre outras questões.

Estes momentos foram de fundamental importância para o diagnóstico da configuração atual do local e das dificuldades específicas de cada família, complementando as visitas. Nas entrevistas pudemos mapear os lotes através das caminhadas transversais, compreendendo a relação das dificuldades e limitações, refletidas no próprio sistema de cultivo. Conhecendo o espaço, levantamos as informações importantes para elaborar práticas que abordassem técnicas possíveis de serem aplicadas de acordo com a realidade apresentada, pensando em seu fortalecimento. Assim, características como as espécies cultivadas em cada lote (árvores e hortaliças), os métodos agroecológicos utilizados e os planos de expansão de cada agricultor(a), foram alguns pontos-chave para as práticas.

A partir das visitas, entrevistas e caminhadas, as dificuldades em relação à produção de alimentos levantadas por todas as famílias estão relacionadas essencialmente a quatro eixos:

1 - Abastecimento hídrico - falta de poços artesianos para abastecer igualmente todas as famílias, e a precariedade do encanamento que direciona a água da nascente para os lotes, que sempre necessita de manutenção; (...) "a água é o maior problema aqui. Ela vem do poço, que todo mundo usa, e hoje está consertado, em boas condições, mas sempre precisa de alguns consertos, e quando acontece isso a gente (os assentados) fica sem nada pra nossa horta e pra casa também”, contou um casal de assentados durante a entrevista. Como vantagem, todas as casas possuem cisternas, implantadas por um projeto, que realizou a construção como uma alternativa de armazenamento de água das chuvas.
2 - Mão-de-obra - as famílias contam, em sua maioria, com somente dois agricultores (marido e mulher) realizando o trabalho diário na terra. Em todas as entrevistas os(as) assentados(as) levantaram a falta de mão-de-obra como fator limitante para produzir e manejar de forma agroecológica sua produção; uma família conta (...) "a gente conhece as técnicas (agroecológicas) e sabe que é importante, mas não dá pra fazer porque é muito trabalho pra nós”.

3 - Parcerias externas - em relação ao escoamento da produção os(as) assentados(as) possuem grandes limitações. Foi a partir de 2016 que iniciaram as parcerias e iniciativas de vendas com a Prefeitura Municipal, restaurante universitário e as Cestas de Alimentos Orgânicos Santa Helena. A questão da articulação de parcerias é preocupante, pois é a garantia de sobrevivência para a maioria das famílias dali, já que dependem da venda dos alimentos que produzem. Somente algumas famílias conseguem, por conta do transporte, vender seus produtos em feiras e, ainda assim "o retorno é muito baixo pela competição que têm entre os convencionais e orgânicos; eles mostram um produto mais bonito por um preço mais baixo, então a gente tem que baixar o preço dos nossos produtos", segundo um assentado.

4 - A comunidade - a articulação das famílias e a ação coletiva no Assentamento ainda está sendo construída, e é uma relação conflituosa. Atualmente não há mais reuniões periódicas entre os(as) assentados(as) para discutir e executar projetos, bem como trabalhos ou parcerias coletivas e reivindicações políticas. A montagem das cestas é a única ação que todas as famílias produtoras e comercializadoras de orgânicos participam. Algumas famílias mencionam nas entrevistas: "é muito dificil reunir todos e planejar/ trabalhar em coletivo"; "tinha reuniões antes pra gente conversar e decidir as coisas juntos, mas agora a gente não faz mais"; "a gente (assentados/ assentadas) têm muito trabalho e ficamos mais nos nossos lotes".

Além desses quatro eixos que conseguimos elencar sobre as dificuldades, existem as potencialidades. Em todas as entrevistas conversamos sobre a questão da adubação dos cultivos, e todos(as) os(as) assentados(as) utilizam esterco de suas próprias criações, não necessitando de insumos orgânicos de fora dos seus sistemas. Além disso, uma questão muito importante a ser citada é a gestão dos resíduos gerados na casa e dos cultivos: todas as famílias possuem criações - gado, galinhas, porcos - e nenhum alimento é perdido, pois o que não está em condições de ser consumido é dado para os animais. No aspecto do ciclo energético, gera-se um excedente no consumo humano e de produção, que é fornecido para os animais e utilizado novamente nos cultivos, ao passo que os animais fornecem alimentos para 
a família e geração de renda.

Outro aspecto muito interessante é sobre a própria agricultura orgânica. Das sete famílias participantes nas cestas, seis relataram nunca ter utilizado agrotóxicos para produzir, mesmo antes de vir para o assentamento. Somente um agricultor, que nos contou toda a sua experiência na agricultura, detalhou sobre sua vivência em uma plantação de algodão, onde realizava a pulverização com agroquímicos todos os dias. $\mathrm{O}$ agricultor relatou ter passado uma intoxicação muito séria e ficou meses internado e, após essa experiência, decidiu nunca mais trabalhar utilizando esses produtos. Ao chegar no assentamento ainda não acreditava que a produção orgânica realmente funcionava, mas começou a produzir e fazer alguns cursos e conta: "acho a melhor forma de plantar e comer, é muito mais saudável”(...) "falaria pra qualquer agricultor fazer desse jeito também”; "Sempre têm dificuldades, com pragas, perdas de cultivos, mas dá pra produzir, a gente tem alternativas, como o caldo de fumo pra pulgões e outras coisas que não precisam usar esses químicos(...); "Quando a gente trabalha plantando é sempre assim, a gente perde as coisas (alimentos) porque faz parte do trabalho também, é natural".

A partir do estabelecimento da ocupação, os(as) assentados(as) iniciaram os cultivos e plantio e nos contaram, ainda, algumas das dificuldades que passaram e que refletem até hoje: uma agricultora nos contou "nada crescia aqui quando a gente chegou. A terra era muito ruim, toda contaminada. Comprei galinhas, elas ficavam soltas e comiam coisas da terra, dai todas morreram no primeiro mês."; (...) “A gente plantava, nada ia para a frente. Ficamos um tempo só plantando e vendo as coisas morrer, para depois conseguir tirar alguma coisa, comer, e só agora nos últimos anos estamos conseguindo vender".

Em conjunto com todas as informações, os diálogos e retratos da realidade e história do local mostram que o assentamento ainda está em processo de transição, sendo o momento atual o de maior produção. Por isso, acreditamos ser de suma importância a questão das parcerias e atuação coletiva, para fortalecer esta fase de transição, e auxiliar no crescimento e estabelecimento de uma produção agroecológica. Através dos diálogos e potencialidades citados acima, pudemos transformar nosso olhar e entendimento sobre o local: vemos, hoje, como um território agroecológico em construção, e constante resistência. As dificuldades sempre estiveram presentes, porém atualmente já houve uma superação gigantesca em relação ao espaço físico, por exemplo.

\section{AÇõES PRáticas - mutirões}

A partir das informações obtidas através dos questionários e entrevistas convidamos os(as) assentados(as) a participar de reuniões, realizadas com o objetivo de apresentar especificamente os trabalhos idealizados pelo grupo.

Nesses momentos dialogamos sobre as possíveis práticas, deixando em aberto a decisão de participação para cada um. Assim, três famílias se dispuseram a participar do trabalho, oferecendo seus lotes para as atividades.

Na primeira prática iniciamos o processo de diálogo sobre os Sistemas Agroflorestais. Realizamos o plantio de batata-doce (Ipomoea batatas), cercada por capim-napiê (Pennisetum purpureum), já plantado pelos(as) agricultores(as), muito utilizado como fornecedor de biomassa e de alimento para o gado, e por uma linha de hortaliças, com o solo exposto. Fizemos a cobertura do solo, dialogando sobre a relação da biomassa, cobertura e exposição do solo, retenção da umidade e aproveitamento de nutrientes. Também fizemos a capina e erguimento de um novo canteiro para o plantio de hortaliças (Figura 1).

Figura 1 - Primeira prática: plantio de batata-doce, erguimento de canteiros e cobertura do solo exposto com matéria seca.

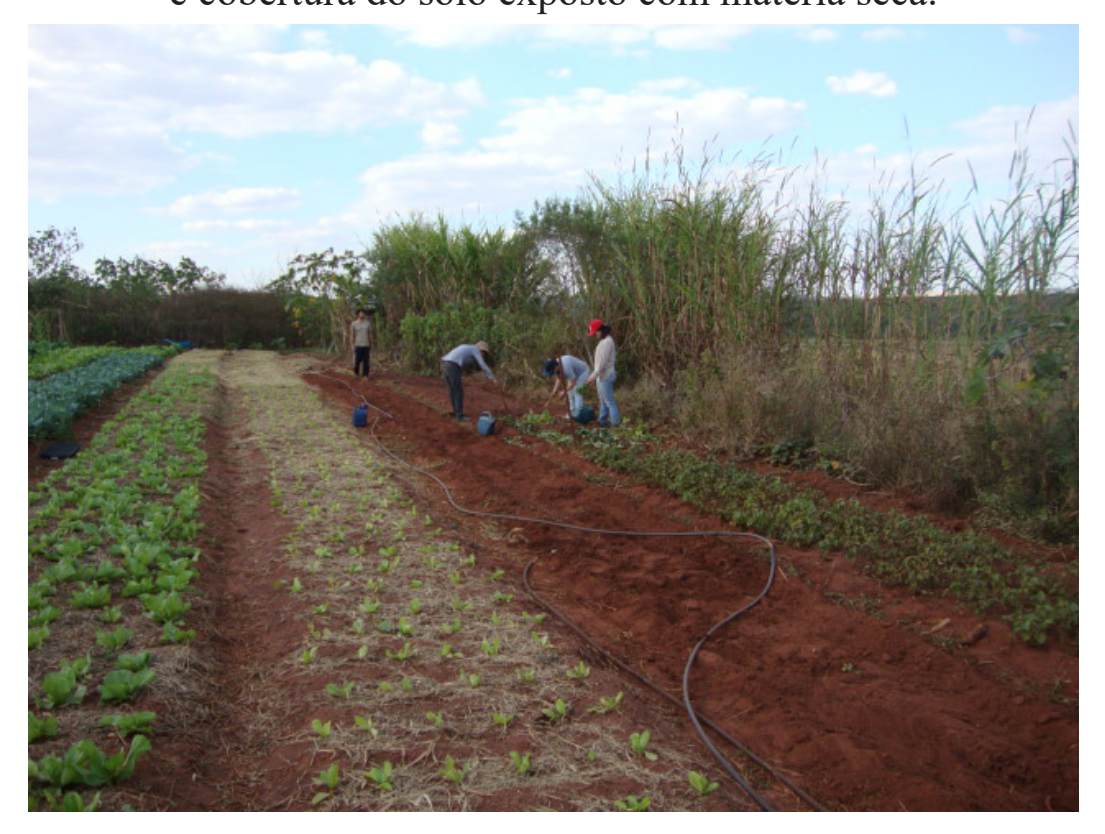

Foto: Rodolfo Antônio de Figueiredo, 2017. 
$\mathrm{Na}$ segunda prática implementamos uma pequena área de plantio agroflorestal: duas linhas de bananeiras intercaladas com mandioca (Manihot esculenta) - distância $5 \times 5 \mathrm{~m}$ entre linhas e $2 \times 2 \mathrm{~m}$ entre plantas - e, entre as linhas de bananeiras, duas linhas de hortaliças plantadas consorciadas (Figura 2). Nossa planta base de biomassa foi a banana-nanica (Musa sp.), utilizada nas linhas externas às hortaliças, para fornecer principalmente matéria de cobertura, umidade para o solo, matéria orgânica e, claro, bananas para consumo e comercialização. As hortaliças consorciadas utilizadas foram pensadas no tempo de colheita, e na relação crescimento/sombreamento, sendo elas: alface (Lactuca sativa), couve (Brassica oleracea), brócolis (Brassica oleracea variedade itálica), repolho (Brassica oleracea variedade capitata), beterraba (Beta vulgaris), cebolinha (Allium fistolosum), rúcula (Eruca sativa) e jiló (Solanum aethiopicum).

Figura 2 - Segunda prática: plantio de hortaliças consorciadas.

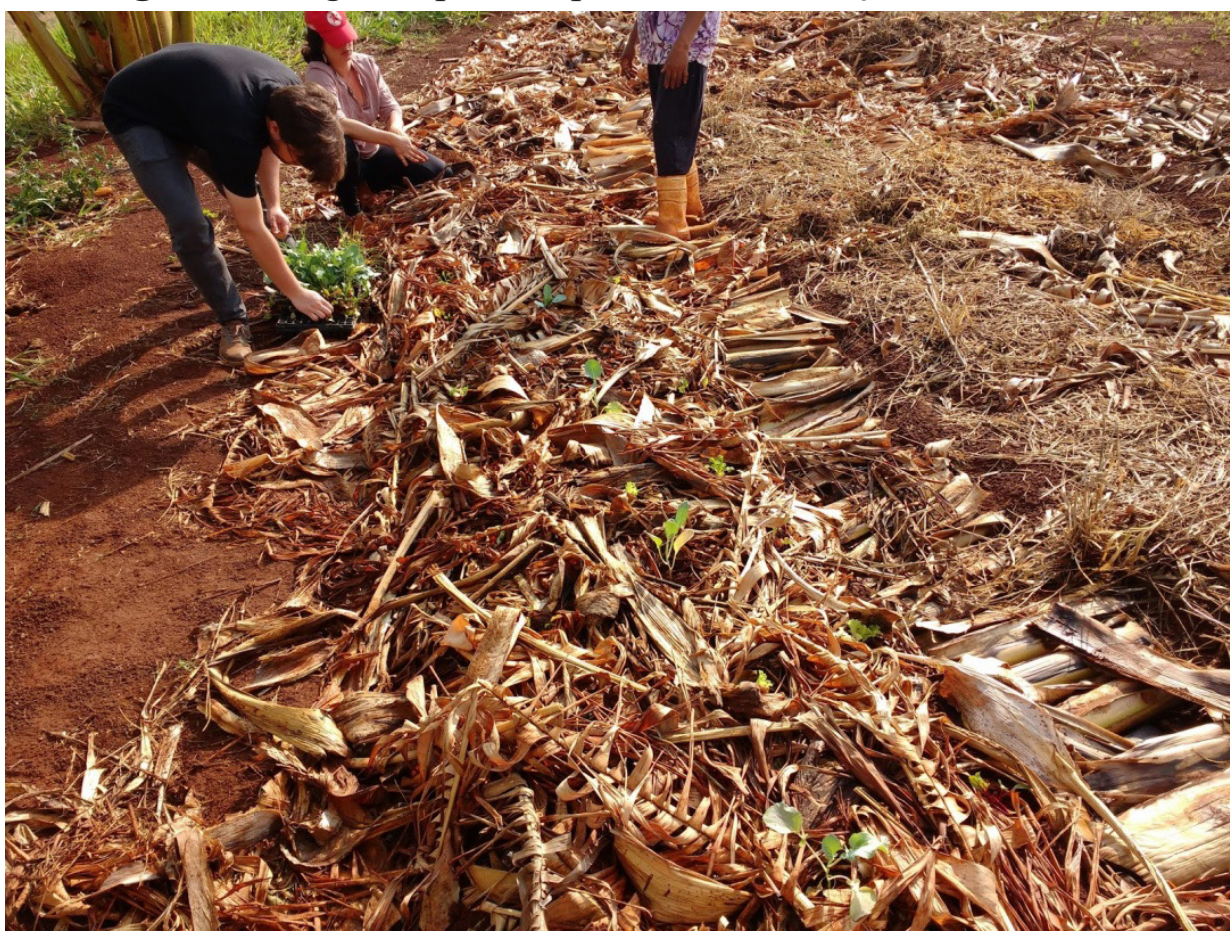

Foto: Lucas Aparecido Ribeiro Antunes, 2017.

A terceira prática foi uma vivência guiada no modelo de Oficina, dada por um Engenheiro Agrônomo convidado pelo grupo a compartilhar suas experiências, e assessorar os(as) assentados(as) através de técnicas que possuem um potencial de fortalecimento das práticas agroecológicas locais. Primeiramente foi feita uma caminhada para conhecer o lote, e algumas dicas de técnicas para eliminar insetos indesejáveis nas hortaliças e nutrição das plantas foram sugeridas. Como prática, foi feito um manejo e preparo de um SAF antigo de frutíferas e nativas $(5 \times 5 \mathrm{~m}$ entre linhas; $2 \times 2 \mathrm{~m}$ entre plantas), para realizar o plantio de mandioca entre as linhas. Além dessa atividade, foi feita uma armadilha para captura de microrganismos eficientes (EM), com arroz cozido deixado em uma área de mata, técnica utilizada para restaurar a microbiota em solos degradados, incentivando a produção de substâncias orgânicas e inorgânicas, benéficas às plantas; um preparado de bicarbonato com açúcar para colocar em olheiros de formigas; técnicas de podas de frutíferas e adubação nos pés de árvores com calcário, esterco e cobertura com matéria seca.

A realização de manejos e a utilização de sistemas agroflorestais voltados para horticultura foram propostos, com a intenção de integrar a realidade dos(as) assentados(as) através do diagnóstico e a visão futura do trabalho, que seria um aumento da produção de alimentos com qualidade nutricional, diversificação das espécies/espaço de terra, contenção natural de pragas (principalmente formigas), e a redução da quantidade de água na irrigação se tornaram guias das nossas práticas.

Os sistemas agrícolas baseados em princípios agroflorestais possuem grande capacidade de resiliência e equilíbrio por respeitarem o conceito de "transição agroecológica", compreendido como um processo gradual e multilinear de mudança, que guiado pelo tempo natural do sistema e manejos adequados (considerados essenciais para uma evolução em aspectos ecológicos), têm potencial de restaurar um ambiente altamente degradado. Assim, aspectos como a reciclagem de nutrientes, a diminuição contínua da dependência externa de insumos e dos custos de produção, o aproveitamento do efeito da biodiversidade no equilíbrio, a economia dos recursos hídricos, além das questões humanas, como emancipação social e econômica dos(as) agricultores(as), são possíveis de serem alcançados (CANUTO, 2005).

No Assentamento Lagoa Grande (Dourado, MS), visualizou-se como saída para restauração da capacidade produtiva dos solos e recuperação ambiental a implantação de sistemas agroflorestais, através de uma metodologia inteiramente participativa (FIGUEIREDO et al., 2008). A implantação dos SAFs trouxe discussão e mobilização local e regional de muitos(as) 
agricultores(as) e, após três anos de trabalho, foi contabilizada produção de 8 ton. de massa seca para cobertura e adubação dos solos, 15 a 20 ton. de matéria verde, representada pelas plantas em desenvolvimento. Através do sistema implantado e das práticas participativas, os(as) agricultores(as) relatam que foi possível visualizar e internalizar os conceitos relacionados à sua funcionalidade, principalmente à viabilidade de produção de alimentos e a não ocorrência de pragas, além do aumento considerável da fertilidade do solo.

Como pesquisadores, pudemos observar e fazer algumas análises em relação ao processo de aprendizagem como um todo. Houve muitas trocas relacionadas a conhecimentos agrícolas específicos, relacionados à produção orgânica e agroflorestal, como ampliação do conhecimento da diversidade de plantas, uso de adubos orgânicos, uso de biofertilizantes, métodos de plantio, entre outros. Além do aspecto prático, o trabalho possibilitou uma melhor compreensão da articulação e funcionamento da comunidade como Assentamento, que consideramos ponto-chave para o desenvolvimento de futuros projetos.

No trabalho executado no Assentamento Rural Prof. Luis D. Macedo (SOBRAL et al., 2009), foi verificado que a implantação de sistemas agroflorestais através de uma metodologia participativa contribui para a aprendizagem e instrumentalização dos conceitos e práticas agroflorestais, de forma que através das técnicas e práticas, os(as) assentados(as) se tornaram aptos(as) a atuar como monitores(as) e facilitadores(as) na apresentação dos sistemas agroflorestais, além do desenho e planejamento de novos SAFs. Segundo os pesquisadores, a etapa de planejamento e desenho dos sistemas, realizada de forma participativa, é fundamental para a construção de agroflorestas na perspectiva agroecológica e libertária.

De forma semelhante, a experiência do Assentamento Sepé Tiaraju/ SP (NOBRE et al., 2009), traz a relação da implantação dos sistemas agroflorestais de forma participativa como uma ferramenta que proporciona troca de experiências entre os(as) agricultores(as) e técnicos(as) envolvidos(as), criando um espaço com grande potencial de aprendizagem. As práticas participativas descritas no trabalho proporcionaram a aproximação do coletivo e fortalecimento da autogestão e emancipação dos(as) agricultores(as), além da validação e apropriação de diversos conhecimentos construídos durante o trabalho.

Apesar do êxito em relação às trocas obtidas através do processo de aprendizagem neste trabalho, algumas expectativas inicias não foram possíveis de serem alcançadas por conta das limitações do tempo de projeto, transporte e disponibilidade dos(as) agricultores(as), inviabilizando possíveis análises quantitativas relacionadas ao aumento da produção, à aplicação de princípios agroflorestais em todos os lotes e participação de todas as famílias. Porém, não consideramos esses aspectos como negativos, mas sim aspectos a serem trabalhados de outras maneiras, e que contemplem a realidade de todas as famílias.

\section{ConClusão}

Consideramos, primeiramente, que o trabalho realizado por nós tem potencial de divulgação da produção por métodos agroecológicos e da realidade dos(as) assentados(as), contribuindo assim para auxiliar futuros projetos e práticas extensionistas. Acreditamos que a Universidade seja uma importante ferramenta de parceria para a comunidade, nas questões de formação e fortalecimento, pois a integração de conhecimentos é, dentro da nossa perspectiva e também da Agroecologia, uma característica essencial e de potencial efeito transformador.

Analisando os quatro principais eixos pautados nas dificuldades, foi possível concluir que todos eles se relacionam intimamente, pois são aspectos que necessitam estar em construção conjunta para o desenvolvimento de uma produção agroecológica. Através das nossas vivências, observamos que essas limitações não são locais, mas elas estão presentes em diversas comunidades produtoras de alimentos orgânicos e agroecológicos, em diferentes níveis.

A produção orgânica e agroecológica através da Agricultura Familiar é realmente um ato de resistência, e sua importância vêm crescendo, apesar de todos os desafios, principalmente de incentivos e parcerias. Como pesquisadores, vemos a questão do reconhecimento e fortalecimento do coletivo o principal eixo a ser trabalhado no local.

A formação de uma proposta de trabalho em que o(a) agricultor(a) pesquisado(a) - mantivesse sua ação como personagem ativo dentro do processo de aprendizagem foi cuidadosamente trabalhada, de forma que as trocas de conhecimentos puderam ser preservadas, sem hierarquizar ou valorizar saberes científicos sobre populares. Assim, os momentos de aprendizagem coletivos se tornaram mais verdadeiros, aplicados de acordo com o que funciona na realidade, e não pautados somente sob uma linha teórica. 
A implementação dos princípios agroflorestais e sua exposição através de práticas coletivas facilitou a visualização do sistema, pois as técnicas em si são bem complexas. Foi surpreendente para nós, pois conseguimos entender durante as vivências no local, que alguns dos princípios agroflorestais se baseiam em conhecimentos populares, ou seja, nasceram originalmente em comunidades e famílias que realizavam cultivo de alimentos em sistemas agroflorestais e foram, ao longo do tempo, agregados aos conhecimentos científicos, que potencializaram seu valor. Isto, para nós, mostra o caráter de uma prática não excludente e aplicável a quaisquer realidades, confirmando que a prática agroflorestal é, realmente, uma forma possível e vantajosa de produção para os(as) agricultores(as) familiares, sustentável e emancipadora.

\section{Agradecimentos}

A autora e o autor agradecem aos assentados(as) pelo acolhimento e ao grupo de extensão que atuou nas vivências, formado por Amanda Maltez Fialho, Lucas Aparecido Antunes, Lucas Sueishi Morales, Renata Maria Guerreiro Fontoura Costa Vaz e Victor Marques Grilli, além de Luiz Adolpho Pratti e Claudio Eduardo S. Nadaleto que partilharam suas experiências conosco nas práticas.

\section{REFERÊNCIAS}

ALENCAR, E.; GOMES, M. A. Metodologia de pesquisa social e diagnóstico participativo. Lavras, MG: UFLA/FAEPE, 1998.

ALTIERI, M. Agroecologia: bases científicas para uma agricultura sustentável. $3^{\text {a }}$ edição. São Paulo: Expressão Popular, 2012.

CANUTO, J. C. Metodologia da pesquisa participativa em agroecologia. Seminário Estadual de Agroecologia do Maranhão, São Luiz-MA, 2005. Disponível em: <https://kapixawa.files.wordpress.com/2010/04/ metodologia_pesq_partic_em_agroecologia1.pdf $>$. Acessado em: 03 set. 2018.

CAPORAL, F. R.; COSTABEBER, J.A. Agroecologia: alguns conceitos e princípios. 24p. Brasília, 2004.

CASADO, G. I. G.; MOLINA, M. G.; GUZMÁN, E. S. Introducción a la agroecología como desarrollo rural sostenible. Ediciones Mundi-Prensa, Barcelona, 2000.

CASELLATO, M. A.; HOLZHACKER, R.; FERNANDEZ, J. M. Redação sem discriminação. Pequeno guia vocabular com dicas para evitar as armadilhas do sexismo na linguagem corrente. São Paulo: Textonovo, 1996.

COSTA, M. B. B. Agroecologia no Brasil: história, princípios e práticas. São Paulo: Expressão Popular, 2017.

EHLERS, E. Agricultura sustentável: origens e perspectivas para um novo paradigma. São Paulo: Livros da Terra, 1996.

FIGUEIREDO, J. de O.; PADOVAN, M. P.; SAGRILO, E.; ARMANDO, M. S; LEONEL, L. A. K.; ALMEIDA, A. S. de. Sistema agroflorestal no assentamento Lagoa Grande, Dourados-MS: uma experiência em expansão. $2^{\circ}$ Seminário de Agroecologia de Mato Grosso do Sul, Embrapa Agropecuária Oeste, 2008.

FRANCO, F. S. Sistemas agroflorestais: uma contribuição para a conservação dos recursos naturais na zona da mata de Minas Gerais. Tese (Doutorado em Ciência Florestal). Universidade Federal de Viçosa, Viçosa, 2000 .

GÓMEZ, J.; LATORRE, A.; SÁNCHEZ M.; FLECHA, R. Metodologia comunicativa crítica. NIASE (Núcleo de Investigação e Ação Social e Educativa): Barcelona, 2006.

KAMIYAMA, A. Percepção ambiental de produtores e qualidade do solo em propriedades orgânicas e convencionais. Dissertação (Mestrado em Agricultura Tropical e Subtropical). Instituto Agronômico de Campinas (IAC), Campinas, 2009.

LOPES, P. R.; SARAVALLE, C. Y.; FRANCESCHINI, G.; FREIRE, L.; CAMARGO, R. A. L.; SILVA, R. C. Problematização participativa da realidade local do assentamento agroecológico PDS Santa Helena - São Carlos/SP. Cadernos de Agroecologia, v.9, n.4, 2014. 
LOPES, P. R.; ARAÚJO, K. C. S.; SILVA, R. C.; SILVA, J. P.; BERGAMASCO, S. M. P. P. Agroecologia e processos de transição no Assentamento Rural Santa Helena. Retratos de Assentamentos, v. 20, n. 2, p. 125-148, 2017.

MAZOYER, M.; ROUDART, L. História das agriculturas no mundo. $4^{\mathrm{a}}$ edição. São Paulo: Ed. UNESP, 2009.

NOBRE, H. G.; CANUTO, J. C.; FRANCO, F. S.; FRANCO, V. F.; SOUZA, T. J. M.; JUNQUEIRA, A. da C. Implantação participativa de Sistemas Agroflorestais no Assentamento Sepé Tiaraju - SP. Embrapa Meio Ambiente (CNPMA), 2009. Disponível em: <http://www.sct.embrapa.br/ cdagro/tema01/01tema24.pdf $>$. Acesso em: 03 set. 2018.

NUNES, P. J.; SILVA, T. B. Implantação de sistemas agroflorestais: a experiência do Assentamento Mário Lago, Ribeirão Preto, estado de São Paulo. Informações Econômicas, v. 46, n. 3, p. 42-53, 2016.

PATERNIANI, E. Agricultura sustentável nos trópicos. Estudos Avançados, v. 15, n. 43, p. 303-326, 2001.

SARAVALLE, C. Y.; LOPES, P. R.; FRANCESCHINI, G.; FREIRE, L.; SOUZA-ESQUERDO, V. F. Projeto de Desenvolvimento Sustentável Santa Helena - São Carlos/SP: problematização participativa da realidade local. Retratos de Assentamentos, v. 19, n. 1, 2016.

SOBRAL, J. P.; SANTOS, J. D.; LE MOAL, M. F.; OLIVEIRA, L. R.; KHATOUNIAN, C. A.; KAGEYAMA, P. Y. Planejamento e implantação participativa de sistemas agroflorestais no Assentamento rural Prof. Luis D. Macedo. Brasília: SBSAF/EMBRAPA/EMATER, 2009. Disponível em: <http://www.sct.embrapa.br/cdagro/tema01/01tema72.pdf $>$. Acesso em: 03 set. 2018.

SOSA, B. M.; JAIME, A. M. R.; LOZANO, D. R. A. L.; ROSSET, P. M. Revolução agroecológica: o movimento de camponês a camponês da ANAP em Cuba. $2^{\mathrm{a}}$ edição. São Paulo: Expressão Popular, 2013.
STEENBOCK, W.; VEZZANI, F.M. Agrofloresta: aprendendo a produzir com a natureza. Curitiba: Fabiane Machado Vezzani, 2013.

TEIXEIRA, R. A.; COUTO, M. S. D. S. Análise dos impactos socioeconômicos e ambientais da expansão da cana-de-açúcar na Bacia do rio Meia Ponte, Goiás. Revista Terceiro Incluído, v.3, n.1, p. 128-143, 2013. 